\title{
Mapping the literature of hospital pharmacyEC
}

\author{
Ann Barrett, MLIS; Melissa Helwig, MLIS; Karen Neves, MA, MLIS
}

See end of article for authors' affiliations.

DOI: http://dx.doi.org/10.3163/1536-5050.104.2.005

\begin{abstract}
Objectives: This study describes the literature of hospital pharmacy and identifies the journals most commonly cited by authors in the field, the publication types most frequently cited, the age of citations, and the indexing access to core journals. The study also looks at differing citation practices between journals with a wide audience compared to a national journal with a focus on regional issues and trends in the field.
\end{abstract}

Method: Cited references from five discipline-specific source journals were collected and analyzed for publication type and age. Two sets were created for comparison. Bradford's Law of Scattering was applied to both sets to determine the most frequently cited journals.

Results: Three-quarters of all cited items were published within the last 10 years (71\%), and journal articles were the most heavily cited publication type $(n=65,760,87 \%)$. Citation analysis revealed 26 journal titles in Zone 1, 177 journal titles in Zone 2, and the remaining were scattered across 3,886 titles. Analysis of a national journal revealed Zone 1 comprised 9 titles. Comparison of the 2 sets revealed that Zone 1 titles overlapped, with the exception of 2 titles that were geographically focused in the national title.

Conclusion: Hospital pharmacy literature draws heavily from its own discipline-specific sources but equally from core general and specialty medical journals. Indexing of cited journals is complete in PubMed and EMBASE but lacking in International Pharmaceutical Abstracts. Gray literature is a significant information source in the field.

Keywords: Abstract and Indexing; Bibliometrics; Libraries, Medical; Hospital Pharmacy

In 2008, hospital pharmacists from around the globe met in Basel, Switzerland, to develop a vision statement of pharmacy practice in a hospital setting. The outcome was a series of statements beginning with: "The overarching goal of hospital pharmacists is to optimize patient outcomes through the judicious, safe, efficacious, appropriate, and cost effective use of medicines" [1].

Recent transitions to a clinical patient-centered model of pharmacy practice now find pharmacists advising prescribing practitioners and, in some settings, providing patient consults. The essential roles of drug preparation and dispensing remain, but increasingly the pharmacist is integrated into the health care team, developing therapeutic patient plans and being accountable for patient health care outcomes [2]. In an institution with an evidence-

Supplemental Table 6 and Table 7 are available with the online version of this journal. based philosophy, a hospital pharmacist seeks to "lead and influence the safety and quality of all aspects of the medication-use process" [3].

This paper describes an effort to establish a list of core publications and databases to help librarians support the information needs of hospital pharmacy professionals. Establishing core lists is particularly relevant as this field becomes more complex and information sources proliferate. One way of identifying core literature for a discipline is through bibliometric study that analyzes citation patterns in a discipline's primary literature. Citation analysis continues a longstanding tradition of mapping core literature by examining which types and ages of material are cited, in which journals cited articles appear, and where those journals are indexed [4]. This study also investigates whether citation patterns differ between high-impact, high-circulation journals and a small, national, peer-reviewed journal with a well-defined and limited geographic readership. The inclusion of a regional journal in the source title mix 
provides insight to potential variations in core titles that should be taken into account when considering collections in different regions and the key sources of information that specific populations rely on in their defined health care systems.

For librarians who support hospital pharmacy services, this study contributes to the evidence guiding collection management decisions in a time of reduced budgets and increasing subscription prices and space pressures. For researchers and practitioners in the field, this study determines which databases provide the most thorough indexing to these journals.

\section{METHODOLOGY}

This study employed the methodology described in the Medical Library Association's Nursing and Allied Health Resources Section mapping protocol [5]. This method involves gathering and analyzing references from a three-year span of articles published in selected "source journals" that are determined to be core in the discipline.

Determining the journals that would serve as the source of data was the initial step of the process. Practitioners in the field were surveyed for their opinions of what they consider to be "core" journal titles and what journal titles they regularly read and rely on for the latest research in the field. The consulted pharmacists were all practicing in the Canadian hospital environment. Other factors considered in source selection were rankings in the "Pharmacology \& Pharmacy" category of the 2012 Journal Citation Reports (JCR) Science Edition [6], as well as core lists such as the Medical Library Association's Master Guide to Authoritative Information Resources in the Health Sciences [7] and the American Association of Colleges of Pharmacy (AACP) Core List of Journals for Libraries That Serve Schools and Colleges of Pharmacy [8]. An early article by Tomasulo [9] identified core journals, two of which were also recommended by the subject experts. Another related study was conducted at the University of Mississippi School of Pharmacy, but that examination was limited to citation patterns of publications of their own faculty [10].

From these lists and recommendations, the authors selected the following journals:

- American Journal of Health-System Pharmacy (AJHP), American Society of Health-System Pharmacists, 154th in the "Pharmacology \& Pharmacy" category of $J C R$, impact factor $(\mathrm{IF})=1.984$
- Annals of Pharmacotherapy, the only non-society source journal, as such offering a slightly different perspective; 106th in the "Pharmacology \& Pharmacy" category of $J C R, \mathrm{IF}=0.567$

- Canadian Journal of Hospital Pharmacy (CJHP), a peer-reviewed journal with a wide readership in the Canadian hospital pharmacy world; serves as the major venue for dissemination of information related to patient-centered pharmacy practice in Canada

- Clinical Pharmacology \& Therapeutics (CPT), American Society for Clinical Pharmacology and Therapeutics, 11th in the "Pharmacology \& Pharmacy" category of $J C R, \mathrm{IF}=6.846$

- Pharmacotherapy, American College of Clinical Pharmacy, 121st in the "Pharmacology \& Pharmacy" category of JCR, IF $=2.311$

All surveyed pharmacists identified their national hospital pharmacy journal (CJHP) as key; therefore, it was decided to analyze and compare this title with the selected US titles. None of the source journals were open access publications, although beginning in 2011, CJHP has had an open archive policy for issues after a six-month embargo.

A database was created in Microsoft Excel once the source journals were identified. Files were created to collect and analyze citation data from each source journal independently as well as in combination. Citations for the 4 source journals were downloaded from the Scopus database, with each having between 15,000 and 23,000 citations over the 3-year span.

Quality control measures were taken to ensure the downloaded data remained complete by comparing tables of contents to downloaded source articles and by manually counting citations and comparing this number to number of exported citations.

Data from CJHP were collected manually due to unreliable indexing in electronic sources. Editorials and erratum were eliminated from the study. Items such as reviews, letters, commentaries, and clinical discussions were included as the citation activity was considerable in those forums and was felt to be relevant.

The information collected for each cited reference included source journal, source year, publication year of cited item, cited item name, volume or issue, format, and reference number. All cited items were stratified into one of five possible formats: "Journal," "Book," "Government document," "Internet," or "Miscellaneous." Books included monographs, chapters, manuals, textbooks, pharmacopeias, and encyclopaedias. Government documents included materials from all levels of government, as well as 


\begin{tabular}{|c|c|c|c|c|c|c|c|c|c|c|c|c|}
\hline & \multicolumn{2}{|c|}{$\begin{array}{c}\text { American Journal of } \\
\text { Health-System } \\
\text { Pharmacy (AJHP) }\end{array}$} & \multicolumn{2}{|c|}{$\begin{array}{c}\text { Annals of } \\
\text { Pharmacotherapy }\end{array}$} & \multicolumn{2}{|c|}{$\begin{array}{c}\text { Clinical } \\
\text { Pharmacology \& } \\
\text { Therapeutics }\end{array}$} & \multicolumn{2}{|c|}{ Pharmacotherapy } & \multicolumn{2}{|c|}{$\begin{array}{c}\text { Canadian Journal of } \\
\text { Hospital Pharmacy } \\
\text { (CJHP) }\end{array}$} & \multicolumn{2}{|c|}{ Total } \\
\hline & no. & $\%$ & no. & $\%$ & no. & $\%$ & no. & $\%$ & no. & $\%$ & no. & $\%$ \\
\hline Journal articles & 12,005 & $80 \%$ & 18,476 & $88 \%$ & 18,594 & $92 \%$ & 14,360 & $89 \%$ & 2,325 & $77 \%$ & 65,760 & $87 \%$ \\
\hline Books & 477 & $3 \%$ & 413 & $2 \%$ & 383 & $2 \%$ & 275 & $2 \%$ & 107 & $4 \%$ & 1,655 & $2 \%$ \\
\hline Government documents & 343 & $2 \%$ & 398 & $2 \%$ & 419 & $2 \%$ & 177 & $1 \%$ & 119 & $4 \%$ & 1,456 & $2 \%$ \\
\hline Internet & 124 & $1 \%$ & 53 & - & 13 & - & 25 & - & 54 & $2 \%$ & 269 & - \\
\hline Miscellaneous & 1,997 & $13 \%$ & 1,559 & $7 \%$ & 892 & $4 \%$ & 1,376 & $8 \%$ & 412 & $13 \%$ & 6,236 & $8 \%$ \\
\hline Total citations & 14,946 & $100 \%$ & 20,899 & $100 \%$ & 20,301 & $100 \%$ & 16,213 & $100 \%$ & 3,017 & $100 \%$ & 75,376 & $100 \%$ \\
\hline
\end{tabular}

Table 1

Format type by source journal and citation frequency

nongovernmental organization sources such as the World Health Organization (WHO). Miscellaneous included databases, drug information sheets, package inserts, grant proposals, society documents, and so on. When citations fell into two potential categories, the item was counted in the more important of the format types (e.g., government document versus Internet). Only citations to web-based sites that contained the primary source of information were counted in the "Internet" format type.

Citations were analyzed from each of the source journals individually as well as in combination, as is usual in mapping studies. In addition, two sets were formed to allow for comparative analysis. Set A included four source titles-CPT, Annals of Pharmacotherapy, Pharmacotherapy, and AJHP - and Set B contained citations from a single source title, CJHP.

The indexing of the top-cited journals was analyzed in three databases that are considered to have wide coverage of the drug literature and are often available to practitioners in their workplace: MEDLINE, EMBASE, and International Pharmaceutical Abstracts (IPA).

\section{RESULTS}

\section{Overall cited items}

Annals of Pharmacotherapy and CPT provided the greatest number of citations, with over 20,000 each, while the AJHP and Pharmacotherapy both provided 15,000-16,000 citations. CJHP, publishing only 6 issues per year, provided 3,017 citations. The average per-article citation rate ranged from a high of 36.4 citations per article in Pharmacotherapy to a low of 13.5 citations per paper in AJHP.
Journal article citations constituted the majority format at $87 \%$ of the total (Table 1). Miscellaneous was the next most frequently cited at $8 \%$. Books and government documents accounted for $2 \%$, respectively, and Internet sources less than $1 \%$. Journal citations maintained significant citation value over a 10-year period, with citation ages of $1-5$ years and 6-10 years each accounting for $34 \%$ of citations (Table 2). Both government documents and miscellaneous had $68 \%$ of their citations in the current 5 years and saw a significant drop after that time span. Books had a more sustained citation pattern over a span of years and did not experience as abrupt a drop off after the 10-year point.

The citation patterns of individual source journals were remarkably similar in the Annals of

Pharmacotherapy, CPT, and Pharmacotherapy, each with citations from journal literature averaging $88 \%-$ $92 \%$. AJHP and CJHP both cited a slightly lower percentage of journal articles $(77 \%-80 \%)$ and a correspondingly higher percentage of miscellaneous, books, and government documents.

Closer analysis of the makeup of the government document and miscellaneous format types clearly elucidated the type of gray literature cited. The largest number of citations in the miscellaneous category constituted product information and package inserts provided by drug companies. Meetings and conference proceedings received a significant number of citations. Many databases were cited (Micromedex, Drugdex, Data-on-File, etc.), but the database with the highest citations overall was the Cochrane Database of Systematic Reviews. Specific citations to Wikipedia only occurred once, which did not reflect the trend that Bould found in a recent study of Wikipedia use in peer-reviewed journal articles [11]. The government documents category was heavily populated with citations from the US Food and Drug Administration, 


\begin{tabular}{|c|c|c|c|c|c|c|c|c|c|c|c|c|}
\hline \multirow[b]{2}{*}{ Publication range } & \multicolumn{2}{|c|}{ Journal articles } & \multicolumn{2}{|c|}{ Books } & \multicolumn{2}{|c|}{$\begin{array}{l}\text { Government } \\
\text { documents }\end{array}$} & \multicolumn{2}{|c|}{ Internet } & \multicolumn{2}{|c|}{ Miscellaneous } & \multicolumn{2}{|c|}{ Total } \\
\hline & no. & $\%$ & no. & $\%$ & no. & $\%$ & no. & $\%$ & no. & $\%$ & no. & $\%$ \\
\hline $0-5$ years & 22,643 & $34 \%$ & 492 & $30 \%$ & 982 & $68 \%$ & 115 & $43 \%$ & 4,263 & $68 \%$ & 28,495 & $38 \%$ \\
\hline $6-10$ years & 22,513 & $34 \%$ & 437 & $27 \%$ & 253 & $18 \%$ & 134 & $50 \%$ & 1,280 & $21 \%$ & 24,617 & $33 \%$ \\
\hline $11-15$ years & 10,236 & $16 \%$ & 304 & $18 \%$ & 121 & $8 \%$ & 11 & $4 \%$ & 225 & $4 \%$ & 10,897 & $14 \%$ \\
\hline $16-20$ years & 4,676 & $7 \%$ & 196 & $12 \%$ & 32 & $2 \%$ & 0 & - & 80 & $1 \%$ & 4,984 & $7 \%$ \\
\hline $21-25$ years & 2,355 & $4 \%$ & 85 & $5 \%$ & 7 & - & 0 & - & 35 & - & 2,482 & $3 \%$ \\
\hline 26 or more years & 3,314 & $5 \%$ & 137 & $8 \%$ & 15 & $1 \%$ & 0 & - & 53 & $1 \%$ & 3,519 & $5 \%$ \\
\hline Unknown & 20 & - & 4 & - & 46 & $3 \%$ & 9 & $3 \%$ & 300 & $5 \%$ & 379 & - \\
\hline Total & 65,757 & $100 \%$ & 1,655 & $100 \%$ & 1,456 & $100 \%$ & 269 & $100 \%$ & 6,236 & $100 \%$ & 75,373 & $100 \%$ \\
\hline
\end{tabular}

Table 2

Publication date of cited references by format

WHO, and legislative and regulatory bodies governing pharmacy practices.

\section{Cited journal articles}

The Set A journals $(n=63,426)$ yielded 3,886 unique journal titles, and Set $B(n=2,331)$ yielded 643 unique titles, together yielding 4,081 unique titles. Titles were ranked in order of decreasing citation numbers, and Bradford's Law of Scattering was applied to the whole as well as to Set A and B separately [12].

Bradford's law groups journal titles into 3 zones in descending order of most cited to lowest cited and predicts that a very small set of journals (Zone 1) will account for a disproportionately large amount of the cited literature [12]. This study revealed that Zone 1 of Set A included 26 journal titles $(0.67 \%)$ accounting for approximately the top third $(33.3 \%)$ of all cited journal articles. Zone 1 of Set B (CJHP) included 9 journal titles $(1.4 \%)$ accounting for the top third (33.3\%). In comparison, a large proportion of journal titles in Zone 3 (Set A, 1,425 (36.7\%); in Set B, 380 $(59.0 \%)$ received only a single citation each (Table 3 ).

\section{DISCUSSION}

\section{Citation types}

Journal articles were the predominant cited format, making up 87\% of all citations (Set A 87\%; Set B 77\%), as would be expected in a field focused on the application of new research findings. Citations to other publication types were heavily weighted to miscellaneous at $9 \%$ (Set $A=8 \%$; Set $B=13 \%$ ), which is foreseeable given that drug manufacturers' information is frequently referred to in clinical practice. The combination of miscellaneous and government documents indicated that gray literature accounted for an average of $9.5 \%$ in 2 of the source journals (Pharmacotherapy, Annals of Pharmacotherapy). $A J H P$ and $C J H P$ had a larger gray literature component, with $16 \%$ in AJHP and $18 \%$ in CJHP. CPT had the lowest gray literature component at $6 \%$. Across all sources, government documents and books composed $2 \%$ of cited materials. Internet-specific sources were not significantly represented, which might reflect the importance hospital pharmacists place on the veracity of the sources they consult.

\section{Citation age}

In total, $38 \%$ of all citations were 5 years of age or newer, and $71 \%$ were 10 years of age or newer. Format types differed in age patterns (Table 2). Journal citations were predominantly $(68 \%)$ in the current 10-year date range (Figure 1). Government documents and miscellaneous were both more heavily weighted to the current 5-year age range at $68 \%$ each. Ninety-three percent of Internet sources fell in the 10-year range. Books had the largest age span, with a significant number of citations in the 20-year range, which may be partly accounted for by core texts refreshed through new editions or updated releases (e.g., Red Book, national formularies, etc.).

\section{Cited journals}

The New England Journal of Medicine was in the top five cited journals of each of the source journals 


\begin{tabular}{|c|c|c|c|c|c|c|c|c|c|c|c|c|}
\hline \multirow[b]{3}{*}{ Zone } & \multicolumn{6}{|c|}{ Set $A$ source journals } & \multicolumn{6}{|c|}{ Set B source journal (CJHP) } \\
\hline & \multicolumn{2}{|c|}{$\begin{array}{l}\text { Cited } \\
\text { journal }\end{array}$} & \multicolumn{2}{|c|}{$\begin{array}{l}\text { Cited journal } \\
\text { references }\end{array}$} & \multicolumn{2}{|c|}{$\begin{array}{c}\text { Cumulative } \\
\text { total }\end{array}$} & \multicolumn{2}{|c|}{$\begin{array}{l}\text { Cited } \\
\text { journal }\end{array}$} & \multicolumn{2}{|c|}{$\begin{array}{l}\text { Cited journal } \\
\text { references }\end{array}$} & \multicolumn{2}{|c|}{$\begin{array}{c}\text { Cumulative } \\
\text { total }\end{array}$} \\
\hline & $\mathrm{n}$ & $\%$ & n & $\%$ & $\mathbf{n}$ & $\%$ & $\mathbf{n}$ & $\%$ & $\mathrm{n}$ & $\%$ & $\mathrm{n}$ & $\%$ \\
\hline 1 & 26 & $0.7 \%$ & 21,186 & $33.4 \%$ & 21,186 & $33.3 \%$ & 9 & $1.4 \%$ & 770 & $33.0 \%$ & 770 & $33.0 \%$ \\
\hline 2 & 177 & $4.6 \%$ & 21,126 & $33.3 \%$ & 42,312 & $66.7 \%$ & 87 & $13.5 \%$ & 781 & $33.5 \%$ & 1,551 & $66.5 \%$ \\
\hline 3 & 3,683 & $94.8 \%$ & 21,114 & $33.3 \%$ & 63,426 & $100.0 \%$ & 547 & $85.1 \%$ & 780 & $33.5 \%$ & 2,331 & $100.0 \%$ \\
\hline Total & 3,886 & $100 \%$ & 63,426 & $100.0 \%$ & & & 643 & $100.0 \%$ & 2,331 & $100.0 \%$ & & \\
\hline
\end{tabular}

Table 3

Distribution by zone of cited journals and references

(Table 4), and all of the source journals appeared in their own top five cited journal list. CPT and AJHP were the only two to have their own journal as the number one cited journal. The trend in the top journals of both sets was to cite pharmacy or pharmacology journals, then general medicine, and finally, some specialty journals. Overall, the journal titles found in Zone 1 and Zone 2 of Set B (CJHP) largely reflected the same titles as those found in Set A (Table 5 and online only Tables 6 and 7). The comparison revealed that Set B included more nonEnglish journal titles (e.g., French) and a much higher number of Canadian titles in both Zone 1 and Zone 2 compared to Set A, which had only one Canadian title appearing in Zone 2 (Canadian Medical Association Journal). This highlights the importance of regional titles to practitioners as sources of information in their specific environments.

\section{Disciplines}

Titles in Zone 1 and Zone 2 clearly indicated that the practice of hospital pharmacy drew on many biomedical fields in addition to its own discipline. Pharmaceutical-related journals were frequently interspersed with titles from general medicine like the New England Journal of Medicine and JAMA. Specialty journals also had a strong presence, with titles focused on areas like cardiology, diabetes, cancer, AIDS, and transplantation appearing throughout all zones. Basic science journals began to appear in Zone 2.

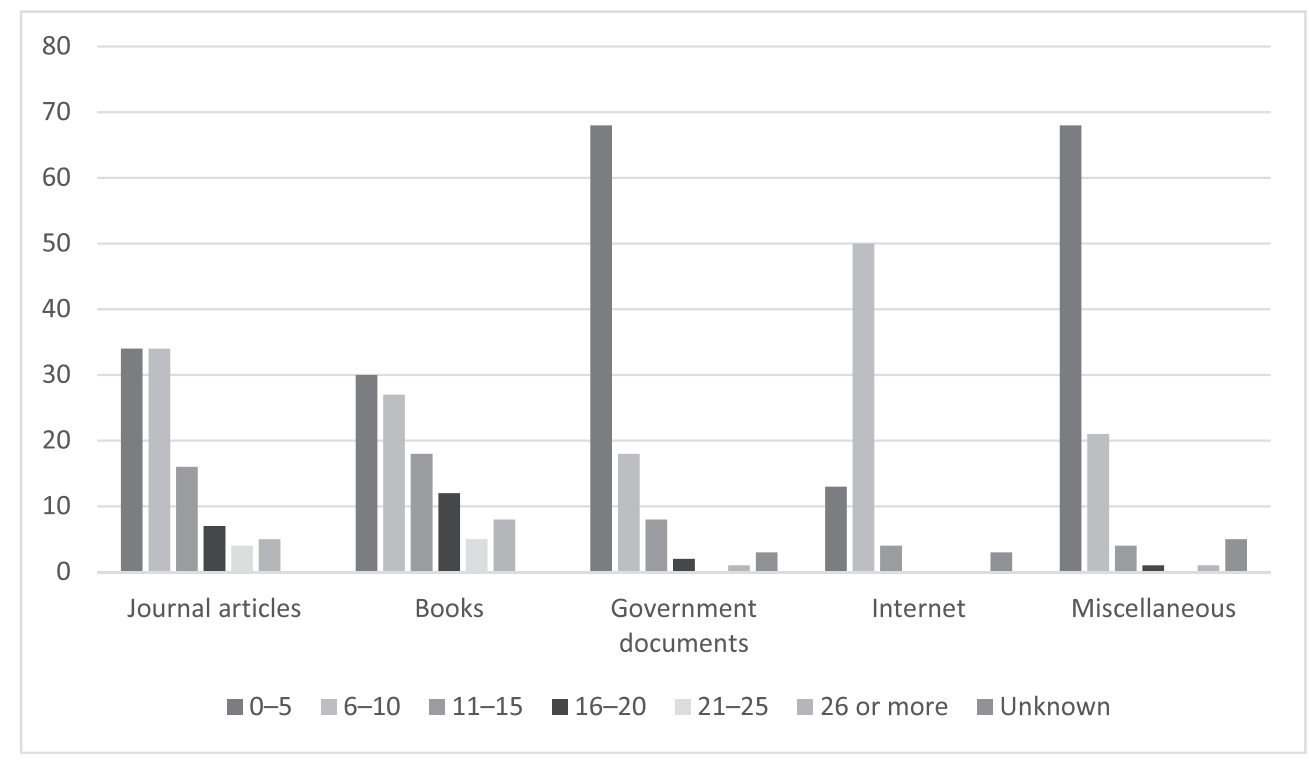

Figure 1

Age in years of cited references by format 


\begin{tabular}{|c|c|c|c|c|c|}
\hline & AJHP & $\begin{array}{c}\text { Annals of } \\
\text { Pharmacotherapy }\end{array}$ & Pharmacotherapy & $\begin{array}{c}\text { Clinical Pharmacology \& } \\
\text { Therapeutics }\end{array}$ & CJHP \\
\hline 1 & $A J H P$ & $\begin{array}{l}\text { New England Journal of } \\
\text { Medicine (NEJM) }\end{array}$ & NEJM & $\begin{array}{l}\text { Clinical Pharmacology } \\
\text { \&Therapeutics }\end{array}$ & AJHP \\
\hline 2 & NEJM & $\begin{array}{l}\text { Annals of } \\
\text { Pharmacotherapy }\end{array}$ & $\begin{array}{c}\text { Antimicrobial Agents \& } \\
\text { Chemotherapy }\end{array}$ & NEJM & CJHP \\
\hline 3 & Pharmacotherapy & Lancet & Clinical Infectious Diseases & $\begin{array}{l}\text { Drug Metabolism \& } \\
\text { Disposition }\end{array}$ & Pharmacotherapy \\
\hline 4 & JAMA & JAMA & Pharmacotherapy & Lancet & NEJM \\
\hline 5 & $\begin{array}{l}\text { Annals of } \\
\text { Pharmacotherapy }\end{array}$ & $\begin{array}{l}\text { Antimicrobial Agents \& } \\
\text { Chemotherapy }\end{array}$ & Lancet & Circulation & $\begin{array}{l}\text { Annals of } \\
\text { Pharmacotherapy }\end{array}$ \\
\hline
\end{tabular}

Table 4

Top 5 cited journals in source titles

\section{Indexing}

MEDLINE and EMBASE provided complete indexing coverage of all of Zone 1 titles; however, IPA coverage was lacking throughout all zones (Table 5). A full list of indexing coverage of both zones is online only. These findings indicate that IPA should not be searched in isolation if comprehensive results are needed.

Indexing inclusion is also a challenge for searchers needing regional information when journals of interest are not included. CJHP is an example of this, when in 1995, they were dropped from the list of

\begin{tabular}{|c|c|c|c|c|}
\hline & & Embase & MEDLINE & IPA \\
\hline 1 & New England Journal of Medicine & $\mathrm{Y}$ & $\mathrm{Y}$ & $\mathrm{Y}$ \\
\hline 2 & Clinical Pharmacology and Therapeutics & $\mathrm{Y}$ & $\mathrm{Y}$ & $\mathrm{Y}$ \\
\hline 3 & American Journal of Health-System Pharmacy & $\mathrm{Y}$ & $\mathrm{Y}$ & $\mathrm{Y}$ \\
\hline 4 & Lancet & $\mathrm{Y}$ & $\mathrm{Y}$ & $\mathrm{Y}$ \\
\hline 5 & JAMA & $\mathrm{Y}$ & $\mathrm{Y}$ & $\mathrm{Y}$ \\
\hline 6 & Annals of Pharmacotherapy & $\mathrm{Y}$ & $\mathrm{Y}$ & $\mathrm{Y}$ \\
\hline 7 & Antimicrobial Agents and Chemotherapy & $\mathrm{Y}$ & $\mathrm{Y}$ & $\mathrm{Y}$ \\
\hline 8 & Pharmacotherapy & $\mathrm{Y}$ & $\mathrm{Y}$ & $\mathrm{Y}$ \\
\hline 9 & Circulation & Y & $\mathrm{Y}$ & Y \\
\hline 10 & Clinical Infectious Diseases & $\mathrm{Y}$ & $\mathrm{Y}$ & $\mathrm{Y}$ \\
\hline 11 & Archives of Internal Medicine (now JAMA Internal Medicine) & Y & Y & Y \\
\hline 12 & Journal of Clinical Oncology & $\mathrm{Y}$ & $\mathrm{Y}$ & $\mathrm{Y}$ \\
\hline 13 & Annals of Internal Medicine & $\mathrm{Y}$ & $\mathrm{Y}$ & $\mathrm{Y}$ \\
\hline 14 & Chest & $\mathrm{Y}$ & $\mathrm{Y}$ & $\mathrm{Y}$ \\
\hline 15 & Diabetes Care & $\mathrm{Y}$ & Y & Y \\
\hline 16 & Journal of the American College of Cardiology & $\mathrm{Y}$ & $\mathrm{Y}$ & $\mathrm{Y}$ \\
\hline 17 & British Journal of Clinical Pharmacology & Y & Y & $\mathrm{Y}$ \\
\hline 18 & Journal of Clinical Pharmacology & $\mathrm{Y}$ & $\mathrm{Y}$ & $\mathrm{Y}$ \\
\hline 19 & Critical Care Medicine & $\mathrm{Y}$ & $\mathrm{Y}$ & $\mathrm{Y}$ \\
\hline 20 & Drug Metabolism and Disposition & $\mathrm{Y}$ & $\mathrm{Y}$ & $\mathrm{Y}$ \\
\hline 21 & Blood & $\mathrm{Y}$ & $\mathrm{Y}$ & $\mathrm{Y}$ \\
\hline 22 & Journal of Antimicrobial Chemotherapy & $\mathrm{Y}$ & $\mathrm{Y}$ & $\mathrm{N}$ \\
\hline 23 & British Medical Journal & $\mathrm{Y}$ & Y & Y \\
\hline 24 & Clinical Pharmacokinetics & $\mathrm{Y}$ & $\mathrm{Y}$ & Y \\
\hline 25 & European Journal of Clinical Pharmacology & $\mathrm{Y}$ & Y & $\mathrm{N}$ \\
\hline 26 & American Journal of Medicine & $\mathrm{Y}$ & $\mathrm{Y}$ & $\mathrm{N}$ \\
\hline Set B Zone 1 & Canadian Journal of Hospital Pharmacy & $\mathrm{Y}$ & $\mathrm{Y}$ & $\mathrm{Y}$ \\
\hline Set B Zone 1 & Canadian Medical Association Journal/* & Y & $\mathrm{Y}$ & Y \\
\hline
\end{tabular}

\section{Table 5}

Indexing of Zone 1 titles in Set A (four titles) and Set B (CJHP) 
journals indexed in MEDLINE and were not reinstated until 2009 [13].

\section{Limitations}

"Academics love the idea of a core list of journals" [14], but there is no ideal process for establishing a core list. The Bradford's Law of Scattering used in this study was first described in the 1930s and is still being discussed in the literature, along with many other methods of determining core lists [15]. Because there is no single method of determining what is core in any specialty, the selection of source journals for a citation study alone is a limiting factor.

Other limitations include erratic indexing of one source title $(C J H P)$, the researcher's reliance on vendor lists for IPA indexing information, format interpretation of some Internet sources, and finally, the management of the volume of citations in this prolific field. The citation sampling method described by Rethlefsen [16] in her mapping study is one option to consider when undertaking research of this size.

\section{ACKNOWLEDGMENTS}

The authors express their thanks to Angela Hersey, Echo Dyan, Maggie Neilson, and Marc Harper for their invaluable assistance with the data coding and journal title authority control portion of this study and to Lindsay McNiff for her sagacious editorial advice.

\section{REFERENCES}

1. The Basel statements on the future of hospital pharmacy. Am J Health Syst Pharm. 2009 Mar 1;66(5 suppl 3):S61-6.

2. Abramowitz PW. The evolution and metamorphosis of the pharmacy practice model. Am J Health Syst Pharm. 2009;66(16):1437-46.

3. Zellmer WA. Overview of the history of hospital pharmacy in the United States. In: Holdford DA, Brown TR, eds. Introduction to hospital and health-system pharmacy practice. Bethesda, MD: American Society of Health-System Pharmacists; 2010. p. 17-37.

4. Baker DR. Citation analysis: a methodological review. Soc Work Res Abstr. 1990;26(3):3-10.

5. Delwiche FA, Schloman BF, Allen MP. Mapping the literature of nursing and allied health professions: project protocol. Chicago, IL: Mapping the Literature of Nursing \& Allied Health Subcommittee, Research Committee, Nursing and Allied Health Resources Section, Medical Library Association.

6. Journal Citation Reports ${ }^{\circledR}$ [Internet]. New York, NY: Thomson Reuters; 2005 [cited 15 Jun 2013]. <http:// thomsonreuters.com/en/products-services/scholarlyscientific-research/research-management-and-evaluation/ journal-citation-reports.html>.

7. Thompson LL, Higa ML, Carrigan E, Tobia R. The Medical Library Association's master guide to authoritative information resources in the health sciences. New York, NY: Neal-Schuman Publishers and Medical Library Association; 2011.

8. Brown C, Ragland N, Shields K, Yff B; Core Journals List Committee of the Libraries/Educational Resources Section. Core list of journals for libraries that serve schools and colleges of pharmacy libraries and educational resources section. 4th ed. American Association of Colleges of Pharmacy; 2010.

9. Tomasulo WJ, Silverman C. Core references for the hospital pharmacy library. Hosp Formul. 1978 Oct;13(10): 793-4.

10. Choinski EM. Journal use in pharmacy: a citation analysis of faculty publications at a school of pharmacy. Sci Technol Libr. 2007;27(3):53-64.

11. Bould MD, Hladkowicz ES, Pigford AA, Ufholz LA, Postonogova T, Shin E, Boet S. References that anyone can edit: review of Wikipedia citations in peer reviewed health science literature. BMJ. 2014 Mar 6;348:g1585. 12. Bradford SC. Documentation. Washington, DC: Public Affairs Press; 1950.

13. Tisdale JE. Indexing of journals in MEDLINE, PubMed, and other bibliographic databases - why not CJHP? Can J Hosp Pharm. 2004;57(2):77-8.

14. Corby K. Constructing core journal lists: mixing science and alchemy. portal: Libr Acad. 2003;3(2):207-17. 15. Nisonger T. The " $80 / 20$ rule" and core journals. Ser Libr. 2008;55(1/2):62-84.

16. Rethlefsen ML, Aldrich AM. Environmental health citation patterns: mapping the literature 2008-2010. J Med Libr Assoc. 2013 Jan;101(1):47-54. DOI: http://dx.doi.org/ 10.3163/1536-5050.101.1.008.

\section{AUTHORS' AFFILIATIONS}

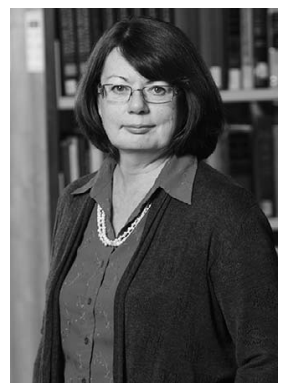

A n n B a r rett, M L IS, Ann.Barrett@Dal.Ca, Head of Public Services; Melissa Helwig, MLIS, Melissa.Helwig@Dal.Ca, Information Services Librarian; W.K. Kellogg Health Sciences Library, Dalhousie University, Sir Charles Tupper Medical Building, 5850 College Street, P.O. Box 15000, Halifax, NS, B3H 4R2, Canada; Karen Neves, MA, MLIS, Karen.Neves@Me.Com, Clinical Librarian, Sidra Medical and Research Center, Doha, Qatar

Received February 2015; accepted October 2015 